\title{
"There's somebody like me": perspectives of a peer-to-peer gynecologic cancer mentorship program
}

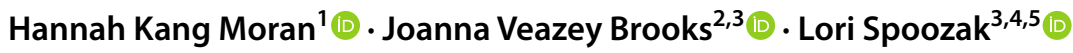

Received: 13 February 2021 / Accepted: 8 June 2021 / Published online: 18 June 2021

(c) The Author(s), under exclusive licence to Springer-Verlag GmbH Germany, part of Springer Nature 2021

\begin{abstract}
Purpose The Ovarian Cancer Research Alliance's Woman to Woman (W2W) program is a peer mentorship program for women with gynecological cancer that was founded in 2004 and has expanded to 43 sites nationwide. An initial program survey was conducted in 2013, but no qualitative studies have investigated patient experiences with peer support programs for gynecologic cancer in the USA. This study examines the match experience at one program site. The aim of this qualitative study was to capture mentor and mentee experiences giving and receiving peer support, including how relationships were initiated and developed.

Methods Hour-long, semi-structured interviews were conducted with both mentors and mentees. Interviews focused on the dynamics of the mentor-mentee relationship. Interviews were recorded, transcribed verbatim, and open-coded. A qualitative descriptive approach was used to organize findings into themes.

Results Sixteen participants $(N=16)$ were interviewed (seven mentors and nine mentees.) Three broad themes emerged: (i) pathways to the program; (ii) how connection occurred; and (iii) themes of compatibility. While program participants universally valued their match experience, frequency and mode of communication, as well as expectations of the match relationship were widely divergent among the program participants.

Conclusion The W2W peer mentorship program is a valuable resource for patients with gynecologic cancer. Refining the wants and needs of mentees including mode of communication, frequency of communication, type of support desired, identifying topics of mutual interest, and introducing the concept of recurrence may improve the connectivity experienced by mentor-mentee dyads.
\end{abstract}

Keywords Mentorship · Support · Gynecologic cancer · Qualitative · Peer

Lori Spoozak

1spoozak@kumc.edu

1 University of Kansas School of Medicine, Kansas City, KS, USA

2 Department of Population Health, University of Kansas School of Medicine, Kansas City, KS, USA

3 University of Kansas Cancer Center, Kansas City, KS, USA

4 Division of Gynecologic Oncology, Department of Obstetrics and Gynecology, University of Kansas School of Medicine, 3901 Rainbow Boulevard, MS 2028, Kansas City, KS 66160-7220, USA

5 Division of Palliative Medicine, Department of Internal Medicine, University of Kansas School of Medicine, 3901 Rainbow Boulevard, MS 2028, Kansas City, KS 66160-7220, USA

\section{Introduction}

Gynecologic cancer patients report high levels of psychological distress, body image issues, and sexual dysfunction [1]. The extent of this distress may be correlated with the level of functional impairment that often results from aggressive treatment (extensive surgery, chemotherapy) required to combat this disease [2]. While treatment options are rapidly expanding to treat advanced disease, many gynecologic cancer patients experience a unique subset of psychological stressors due to notoriously poor prognostic outcomes and also because the body parts involved are endowed with meaning, associated with sexuality, fertility, and feminine identity [3]. It has been established that women with gynecologic cancer routinely need extensive social and emotional support to cope with their conditions [3, 4]. Gynecologic cancer, especially when compared with breast cancer, is less 
prominent in public discourse [5], which could also contribute to feelings of isolation and lack of awareness in patients and their potential supporters.

Peer to peer support has become increasingly popular as an intervention to alleviate some of this distress. Peer coaches or mentors are individuals who have successfully coped with the same condition or surgical procedure, who serve as positive role models and provide a unique level of hope and understanding [6]. There is ample evidence that receiving one-to-one peer support is beneficial to patients with cancer [7-9]. However, compared to other peer support interventions for cancer patients, one-to-one mentoring is still underexplored in the literature [8]. Given the drastic increase in internet usage, social media, texting, and other modalities of electronic communication, coupled with the COVID-19 pandemic limiting in-person interactions, it is important to examine the experiences of peer mentorship in the context of these new realities.

The Ovarian Cancer Research Alliance's (OCRA) Woman to Woman (W2W) program, founded at Mount Sinai Medical Center in 2004 [10], is a peer mentoring program that pairs gynecologic cancer survivors with newly diagnosed gynecologic cancer patients. Through this program, survivor volunteers provide emotional support and mentoring to new patients, through one-on-one relationships. The OCRA supports the development of new programs across the nation. In 2019, the University of Kansas Medical Center received a start-up grant from OCRA to fund the creation of a W2W program, training nine mentors. Seven mentors were matched with nine different mentees in the first cohort of participants. A limited survey of mentees was executed at the original program site in 2013 [7], but a qualitative evaluation of participants experiences has not been performed. We investigate the experiences of both mentors and mentees who are giving and receiving peer mentorship through Woman to Woman at the University of Kansas Health System, a program of the Ovarian Cancer Research Alliance.

\section{Methods}

This study used a qualitative descriptive design [11] with narrative analysis overtones [12]. Qualitative descriptive studies draw from the general tenets of naturalistic inquiry, which upholds one primary commitment: to study something in its natural state, without manipulation of variables or an a priori commitment to any one theoretical framework [11].

\section{Peer support intervention}

The W2W program at the University of Kansas is coordinated by a physician champion, and two program coordinators, a gynecologic oncology nurse and gynecologic oncology social worker. The gynecologic oncology care team, the physician champion, and the program coordinators identified potential participants from their patient base. The mentors and mentees were approached directly by the program team and the gynecologic care team. Initially, there were flyers available for the program. However, due to COVID-19 restrictions, paper materials like flyers were removed from the waiting rooms and treatment rooms. Prospective mentors had been previously diagnosed with gynecologic cancer and were in remission. When a mentor experienced disease recurrence after the start of the program, they were given the option of withdrawing, delaying, or continuing to serve as mentors, depending on whether they felt clinically stable. Prospective mentees were newly diagnosed or entering a new phase of treatment. Mentors and mentees were matched by the program coordinators primarily based on a pre-match survey on which participants indicated the importance of certain factors (age, type of cancer, children). Program coordinators spoke to the mentors and mentees prior to the training and the match to ensure the participants did not have untreated mental illness requiring support beyond the scope of the peer mentoring relationship.

Mentors were encouraged to reach out to their mentees as soon as they were matched. $\mathrm{W} 2 \mathrm{~W}$ program coordinators checked in with the mentor directly after first contact to ensure the match was agreeable, and then continued to contact mentors approximately every 3 months. At the time when our study was conducted, nine mentees and seven mentors were engaged in active mentorship at our institution.

\section{Peer mentor training}

The initial training took place on January 31, 2020, prior to the COVID-19 outbreak. Nine mentors attended a halfday in-person training led by program coordinators. The training included both experiential and didactic activities. First, an introduction to the Ovarian Cancer Research Alliance's Woman to Woman program was provided and mentors were familiarized with the 1:1 structure of the program. General principles of mentorship were then discussed, with an emphasis on active listening, empathy, and thoughtful self-disclosure. Mentors were encouraged to reflect on their cancer journeys and share with the group what they felt to be their greatest accomplishments. A meditation activity aimed at reflection was conducted. Anticipated difficult issues were discussed, and it was emphasized that mentors should escalate any critical concerns with the $\mathrm{W} 2 \mathrm{~W}$ program coordinators. A boundaries worksheet was also completed in which mentors were presented with several scenarios and were directed to select the most appropriate response. Not giving medical advice was an additional topic that was emphasized. It was also emphasized that the role of the mentor is to meet the supportive needs of the mentee, and that the mentors 
should navigate frequency and modality of contact with their mentees. Prior to COVID-19, face to face interactions were encouraged. After the COVID-19 pandemic began, mentors and mentees were advised to follow safety guidelines and shift their interactions to virtual modalities.

\section{Study procedure}

All women currently participating in the Woman to Woman at the University of Kansas Health System, a program of the Ovarian Cancer Research Alliance, were identified as potential study participants. Each was contacted via telephone and provided an overview of the study. Interested participants provided verbal consent and participated in a video conference or telephone interview. Demographic information was collected at the beginning of the interview, and interviews followed a guide created by the researcher in collaboration with a senior investigator with extensive experience in qualitative health research. The main areas of interest were (i) understanding the motivators of participating in the program; (ii) identifying program strengths and weaknesses; (iii) understanding the nature of the mentoring relationship; and (iv) examining how COVID-19 impacted the mentoring relationship. Interviews were audio recorded and transcribed verbatim for analysis. The study was approved by our Institutional Review Board.

\section{Data analysis}

Transcripts were reviewed initially multiple times with one research team member making exploratory notes on each transcript. All three authors open-coded three interviews that informed codebook development. This final codebook, including codes and definitions, was used to code the remainder of the interviews, with one research team member assigning primary codes and a second coder reviewing. Themes and illustrative quotations were organized in a matrix. NVivo 12 was used to manage this analysis [13].

\section{Results}

Seven mentors and nine mentees were interviewed $(N=16)$. Two mentors were paired with two mentees each, and one mentee agreed to participate, but was unable to be interviewed due to progressive health issues. Otherwise, all initial program matches were interviewed. Demographics are included in Table 1. Three key themes were identified: (i) pathways to the $\mathrm{W} 2 \mathrm{~W}$ program; (ii) how connection occurred; and (iii) themes of compatibility.
Table 1 Participant demographics $(N=16)$

\begin{tabular}{|c|c|c|c|}
\hline \multicolumn{2}{|l|}{ Mentors $(N=7)$} & \multicolumn{2}{|l|}{ Mentees $(N=9)$} \\
\hline Age (years) & & Age (years) & \\
\hline Median & $62(43-73)$ & Median & $62(53-73)$ \\
\hline Race & & Race & \\
\hline White & $5(71 \%)$ & White & $8(89 \%)$ \\
\hline Black & $2(29 \%)$ & Black & $1(11 \%)$ \\
\hline Marital status & & Marital status & \\
\hline Married & $5(71 \%)$ & Married & $8(89 \%)$ \\
\hline Single & $2(29 \%)$ & Single & $1(11 \%)$ \\
\hline Cancer type & & Cancer type & \\
\hline Ovarian & $5(71 \%)$ & Ovarian & $7(78 \%)$ \\
\hline Endometrial & $2(29 \%)$ & Endometrial & $2(22 \%)$ \\
\hline Year diagnosed & & Year diagnosed & \\
\hline 2018 & $4(57 \%)$ & 2020 & $7(78 \%)$ \\
\hline 2017 & $1(14 \%)$ & 2019 & $1(11 \%)$ \\
\hline 2001 & $2(28 \%)$ & 2017 & $1(11 \%)$ \\
\hline
\end{tabular}

\section{Pathways to the W2W program}

For participants, the $\mathrm{W} 2 \mathrm{~W}$ program presented a unique opportunity to connect with other women in the same geographic area who had experience with gynecologic cancer. Prior to W2W, participants reported looking for support, connection, and first-hand information through several avenues. One participant spoke about a social media group. One participant attended a camp for gynecologic cancer patients. Another participant left encouraging messages on chat boards. One more participant had another mentor through another national network.

Seven mentees spoke about how they joined the W2W program specifically for the opportunity to speak to someone with a similar cancer experience. Two other mentees were more hesitant and approached the program with a "can't hurt" attitude. One of these two participants decided to participate when her doctor confirmed that "I could make of it... as I wanted..." (Mentee A). Another mentee had a close friend with ovarian cancer but was enthusiastic about the W2W program because she wanted "somebody else to talk to that would be very independent of my friendship with my friend" because, she explained, "I didn't want to always talk about myself all the time with her, because she's going through a lot of stuff too" (Mentee D).

Two mentees who were going through recurrences were interested in the program because of the "survival records" of their mentors. One mentee said of her mentor:

"I guess I didn't know what to expect until I heard [DOCTOR] say that [MENTOR] was... a stage 4 survivor for like 19 years... and I thought 'well that's 
of interest to me, cuz that's a good record. That's of higher stakes than even I had.'"-Mentee B

\section{How connection occurred}

\section{Modalities}

Within the W2W program, while participants were not able to meet in person due to COVID-19, all mentors and mentees had some form of contact. Some pairs emailed, some regularly talked on the phone, some texted, and some are friends on social media.

The convenience of virtual connection was preferable to some. One mentor-mentee pair found that being friends on social media worked well for them. The mentee explained how when she was first diagnosed, she "really didn't want to have another conversation with someone about cancer" so she said, "Let's text." She and her mentor texted initially to exchange information about treatment, but they communicate primarily over social media now because "people are busy" and the mentee found that between all of her appointments, social media was easier. She described her relationship with her mentor:

"I see what she's up to, and see pictures of her, she sees me. It's not very often, but you know, just every once in a while [she] put[s] something fun up on my wall, which is perfect for me. I don't really need someone to converse with back and forth, if I did...I know that she's there."-Mentee D

The mentor said of their virtual relationship:

"I've still never talked to her in person or...even on the phone, but it's just through [SOCIAL MEDIA] or texting. And I think that's what she's comfortable with, which is cool...I feel like I'm doing her a service without getting too personal. It kinda takes that emotion out of it."-Mentor Y

Participants' perceptions of what was considered "personal" varied. Interestingly, the mentee noted that being able to see photos of each other as well as life events as captured on social media in some ways made the relationship more personal. She said, "We can see each other you know, not just texting or talking but we can see what each other looks like. Sometimes that makes it more personal. It's just fun" (Mentee D). Another participant, who had only spoken to her mentor on the phone, recognized that it was "probably easier to connect" with someone over video conference but, she said, "[VIDEO CONFERENCE] is scarier to mebecause then you do have a real face" (Mentee E).

Modalities of connection varied widely, and a few participants believed that their mentorship experience may have been stronger if they had been able to meet in person. One mentor said, "I do think, um, this COVID-19 thing...it's a shame that it happened so new into this program because I do think it's changing how people are connecting for that" (Mentor X). Another mentor spoke about how she wished she could get together for a cup of coffee with her mentee or attend a treatment with her-activities that were "Just something, just more, just a little deeper relationship than just a couple of text messages" (Mentor W).

\section{Frequency}

The W2W program left room for participants to negotiate the frequency of interactions. Several mentees spoke of themselves as being low-maintenance and "not needing a lot" from their mentors. One mentor said of her mentee, "I think she just kinda signed up to have that support if she needed it, I don't think she was really looking for, you know a super strong relationship with someone" (Mentor Z). Another mentee said of her mentor, "She offered for me to call her if I needed anything. Just having that possibility was great" (Mentee F). One mentee was already thinking about the future of her relationship with her mentor. She said, "And you know, if everything's good for you know, 6, 7, 8 months, then I might cut it off... with the thought in mind that I could always get back with her if a year from now something else is going on" (Mentee A).

Two mentors and three mentees expressed concern over "bothering" their respective mentees and mentors in reaching out. One mentee spoke about how she was reluctant in general to "bother" people but her post-chemotherapy body aches became so unbearable that she decided to call her mentor (Mentee G). Another mentee said she didn't want to "just buzz up anytime" to contact her mentor (Mentee A). One mentor spoke about not wanting to "push" contact with her mentee because "I knew she was having her surgery and after you have that, you're so out of it and I didn't want to be a bother to her" (Mentor Z).

Even though not all mentees wanted frequent contact, some mentors were intentional about conveying their unconditional availability. One said:

“... I didn't go into it I guess with that um, attitude that 'You're sick and I'm not' or 'you can call me up at this time' 'you can call me at 1 o'clock on Wednesday 5 o' clock on Mondays and never on a Sunday or never on a Saturday or Sunday.' There was no boundaries. I didn't give her any boundary. And because that's not, that's not a good thing to do to anyone that's sick."Mentor V

Two mentors were surprised that their mentees wanted such minimal support and interaction. One mentor said her mentee "came right out and said... 'I don't really think that I need anyone, but you know...we can talk every now and 
then or whatever"' (Mentor W). Another mentor had spoken with her mentee three times, but the second two times felt "rushy, like, she didn't really want to hear anything that you had to say. She wasn't really interested in talkin"" (Mentor $\mathrm{U})$.

\section{Themes of compatibility}

\section{Compatibility}

Participants appreciated having a mentor or mentee that was at a similar stage of life with a similar cancer diagnosis and treatment course. Two participants spoke about how having a mentor with the same cancer or undergoing the same treatment was helpful to compare experiences and know what to expect in terms of treatment side effects. One mentee who was being treated for a recurrence specifically wanted a mentor who had experienced a recurrence:

"I met people who live in [TOWN] who have had ovarian cancer and have been through it...but none of them have recurred. That's the thing. So I feel like when you don't recur, you're one and done, you're kind of in the separate group where you don't recur, so for me, knowing that [MENTOR], it was nice, it was nice when I found out that she had recurred because... that gave me interest to talk to her."-Mentee B

Another mentee spoke about how helpful it was to speak to someone who underwent the same chemotherapy regimen. She said of her mentor, “...She's been able to tell me what to expect. The first chemo treatment, nobody knows what you're going to, I mean it's just an unknown. But every time she's able to help me, [saying] 'Yeah I had that,' and she's just very encouraging" (Mentee G). Two other participants spoke about how they enjoyed being of similar ages and life stages as their respective mentor and mentee. One mentor said she was interested in the program specifically because she would be matched with someone her age.

"Most people that I knew that um, I met on [SOCIAL MEDIA] or wherever chat groups, they were in their fifties and sixties, seventies, so a lotta the things that affected me like having kids still in school, being, I mean, married, $[X X]$ years old, you still...have sexual interest in your spouse. Going through cancer, especially gynecological cancer, there's a lot of questions you have that there just really weren't resources for, for younger people."-Mentor Z

Even beyond having similar cancer experiences, one mentor-mentee dyad got along particularly well. The mentee said, "I mean, we both like to gab" (Mentee G).

While some participants did express compatibility along certain factors, ultimately, what was most important in binding these women together was the experience of having ovarian cancer.

"So that's why I think the mentor program is especially good and also early on, I felt like you know, you're an only child and you hear that there might be other children but you just don't know where they are or what they look like. And then you find them and you're like 'oh my god...there's somebody like me,' you know, I mean they didn't necessarily look like me or... have the same life, but there is a camaraderie that comes from that because you know where they've been and they know where you've been. Does that make any sense?"-Mentor X

A comprehensive list of information shared between mentors and mentees is included in Table 2.

\section{Incompatibility}

Mentors and mentees made sense of their illness in various ways, and some relied heavily on faith, others on diet change or alternative healing treatments, and some stayed off the internet while others extensively researched their conditions. Occasionally, differences in approaches were significant enough to be spontaneously mentioned by our participants. Two mentees spoke about how they would prefer more science-based support.

To improve mentor-mentee matching, the one mentee suggested:

"Maybe they should ask if the person knows, are you wanting a mentor to talk science? Are you wanting a mentor to talk emotions? Or do you want someone to talk both? Because people are gonna be better at one than the other. But I mean that's all, very subjective, so I don't know..."-Mentee H

One mentor spoke about how during her cancer journey, she made drastic lifestyle changes that she believed improved her health and how difficult it was for her to watch her mentee not follow her advice. She said:

"I was pretty hardcore. I didn't do any, I cut out everything from sugar to caffeine to alcohol to meat, I mean I was just straight vegan. And felt great and you know she'll like post a picture on [SOCIAL MEDIA] and she's like drinking alcohol or eating like a fried foods...So, that was the hardest part for me was not taking that like, personally."-Mentor Y

Additionally, three mentees noted that having a mentor who had a recurrence shifted the dynamics of their mentoring relationship. One mentee, who was finishing her treatments, said it seemed like an "I'm done and she's not" situation with her mentor. Another mentee was initially paired 
Table 2 Information shared between mentor and mentee

\begin{tabular}{|c|c|}
\hline Category & Illustrative Quotations \\
\hline iet and lifestyle & $\begin{array}{l}\text { “'Um, did your life look any different after your first recurrence, you know? What'd you do differently?'...It was nice to } \\
\text { be able to ask for that and hear what she said and you know, I, I don't eat a lot of sugar because I know it's not good, } \\
\text { of course we know that, but I mean it was funny because she said 'I don't eat much sugar either' but then she said } \\
\text { 'I'm also not freaked out about it because... if sugar killed you... I'd be dead right now!' ...I was just very curious like } \\
\text { 'What did you do?' Cuz some people just go completely you know, very strict. And then other people are like 'I'll eat } \\
\text { whatever I want!' Which is not what I do. But it was just nice to hear. I'm just curious to ask about what of lifestyles } \\
\text { she has.”-Mentee B } \\
\text { "[I say] '[MENTEE], this is a whole different ball game. First you gotta get better. You gotta get back to normal...if } \\
\text { there is such a thing. Get back to where you feel like your old self. Then worry about your weight! Don't worry about } \\
\text { your weight! Don't worry about staying, you know, on your treadmill and going and walking around, the, the uh, trail. } \\
\text { Don't do that! You gotta calm down, just take it a day at a time.’”-Mentor V }\end{array}$ \\
\hline Alternative therapies & $\begin{array}{l}\text { "Well you know, she was kinda the thing that pushed me over the edge, so to speak, of doing this [VITAMIN C THER- } \\
\text { APY], I had, like I said, read about it and I was interested in it, but I mean it's kind of expensive you know, um, and it's } \\
\text { not covered by insurance, but I don't know, after talking to her and um, she said she definitely didn't think it hurt, she } \\
\text { said 'I don't know but I don't think it hurt me for sure.' So, I thought, why not."-Mentee B } \\
\text { "And so she just started asking me more questions about like 'Who did you use for acupuncture, what did you think?' } \\
\text { And just little details about the things I did. So I just went back and forth with her."-Mentor Y }\end{array}$ \\
\hline Self-care & $\begin{array}{l}\text { "Well, I just ask her (mentor,) you know, what did she actually do for her 'me time,' you know? Like, when you're going } \\
\text { through that, you have to take some time out to actually - whether it's read a book or watch a good movie. Or you } \\
\text { know, maybe have somebody do your nails. Somebody safe, of course. You know, just what kind of things did she do } \\
\text { for her 'me time.' You know? She kind of shared those things with me."-Mentee C }\end{array}$ \\
\hline Post-chemotherapy & $\begin{array}{l}\text { "'Listen to your body!' I don't know how many times she's (mentor) told me that and, it just, finally clicked and so this } \\
\text { last one, knowing I was tired on Thursday and Friday... Saturday and Sunday I pretty much didn't get out of bed until } \\
3 \text { o'clock and Monday...[I] slept pretty much the whole day and so yeah. She's shared it with me. And helped, it's } \\
\text { amazing we've experienced a lot of the same[SIDE EFFECTS,] and lack of side effects.”-Mentee G } \\
\text { "I said, 'You're gonna have days where you think oh my gosh, I feel HORRIBLE, is this what it's gonna be like?' NO. } \\
\text { It's not. You're gonna have a day or two where you're gonna feel kinda yucky, but it's not gonna last. It's gonna go } \\
\text { away and you're gonna feel great again. So just on those days where you feel kinda yucky, just rest. And let it, that's a } \\
\text { good thing, that means the chemo is working. And then just kinda be thankful you feel yucky cuz that means it's work- } \\
\text { ing and you'll be fine. I said anytime I felt yucky I said, 'It's ok this is temporary, you deserve a day to rest for a couple } \\
\text { days..."--Mentor Y }\end{array}$ \\
\hline Hair loss management & $\begin{array}{l}\text { "[MENTEE] was having a hard time at first when her hair, when she started chemo and her hair started coming out and } \\
\text { I said, 'Ok [MENTEE], think about it...Would you rather be bald, and alive, or dead with hair down to your butt?'”- } \\
\text { Mentor V } \\
\text { "So, she (mentor) told me what she did for it, you know. What she used on her end, and what worked for her. So, I had } \\
\text { already come to the conclusion that...I was losin' my hair, because the doctor had told me that. I just didn't know that } \\
\text { it was going to be that same day that my mentor called me, so she kind of eases me down, and made me feel more } \\
\text { comfortable about it. And I told her, I said, 'Well, I've already made my mind up, and the way it's coming out now, I } \\
\text { just told my husband, he's gonna be a part of it, so, he'll be buzzin' it out."' [laughing]-Mentee C }\end{array}$ \\
\hline
\end{tabular}

with a mentor who was 30 years younger and who was potentially having a recurrence, which resulted in a reversal of mentor and mentee roles.

"I had that feeling that I was helping her. I mean, we were talking about, you know, how it changes our lives forever. Forever. It's kind of a grief sort of thing." Mentee E

\section{Discussion}

The W2W program facilitates connections between gynecologic cancer patients to provide peer support and mentorship. Our participants actively sought advice from individuals with similar disease and appreciated connecting through the program to a mentor, and communicating via text, social media, or telephone. Frequency of communication varied, and both mentors and mentees were sensitive about not burdening the other. While connecting over a shared cancer experience was powerful, some mentees also desired additional demographic similarities to their mentor. Additionally, some participants sought emotional support, while others were looking for medical knowledge. When recruiting future patients, it is important to reiterate that contact with their mentor can be as frequent or intense as desired. In fact, many mentees reported a sense of security and support knowing they had the potential to contact their mentor, but in actuality had relatively little communication.

The COVID-19 pandemic required adapting the W2W program to be entirely virtual. Future iterations of mentor training will include optimizing technology for mentorship. 
Fig. 1 Matching process considerations

\section{Open-ended, pre-match questionnaire for mentees}

1. How frequently do you want to speak with your mentor? Once a week? Once a month? Once every couple of months?

2. How do you think you will want to connect with your mentor? Via text? Telephone? Social Media? Email? Video Conference?

3. What are some topics you'd like to speak to your mentor about? Chemotherapy? Hair loss? Sexuality? How to prepare for surgery? Religion? Exercise? Eating well? Talking to friends and family? Complimentary and alternative medicine?

4. Are you seeking emotional/social support outside of your friends or family?

5. How important is it to you to have a mentor who is willing to speak about the more medical/scientific aspects of your diagnosis?

6. Many women with gynecologic cancer go through multiple periods of recurrence (cancer coming back) and remission (cancer going away.) Are you comfortable having a mentor who is having a recurrence or undergoing chemotherapy if they feel well and stable enough to support a mentee?
Program funding should be directed toward ensuring each mentor and mentee has access to $\mathrm{Wi}-\mathrm{Fi}$ as well as a device through which to communicate. Mentors should be made aware that their mentees may not desire a virtual face-to-face experience and may be more comfortable with texting or connecting via social media. While programs exist nationally to connect gynecologic cancer patients from all over the country $[14,15]$, our participants noted the importance of connecting with someone regionally, and the shift to virtual communication may also facilitate this in a rural state. Finally, healthcare systems should take advantage of the now robust electronic medical record system to deliver "support bundles" to their patients, containing links to resources and support groups [16]. Recruitment to the W2W program may be offered as part of the intake process to every newly diagnosed gynecologic cancer patient.

We identified factors that made participants feel more connected and compatible to their mentor and mentee, but it is important to note that similar to a previous study of gynecologic cancer mentees in the UK that found "some women felt understood and helped by supporters who differed substantially from them" [5], our participants did not always need or want concordance across all demographics to have a successful match. Our data suggests that matches may be more successful, however, if mentees are able to indicate their preferences for the mechanics of the relationship and identify other characteristics they find important in a mentor, such as a willingness to talk about sexual relationships or understanding of science. Based on our findings, we designed a list of critical questions to ask mentees prior to being matched with a mentor in order to best align compatibility (Fig. 1). This list of questions, however, should be asked with the understanding that interactions between mentor and mentee should not be overly protocolized, because such strict interventions may impede the mentors' abilities to form genuine connections with their mentees [17].

Cancer recurrence in $\mathrm{W} 2 \mathrm{~W}$ mentors emerged as a pressing issue that has the potential to change the therapeutic mentoring relationship. Recurrence is common in high-risk ovarian and uterine cancer [18]. It is important to acknowledge that both mentors and mentees may respond differently to a recurrence. Mentors devote a large amount of time to attending the training and have a strong desire to help others, so to prohibit them from being matched due to a recurrence, or to require that the match end due to a recurrence could be harmful and contradict the supportive mission of the W2W program. This must be weighed against potential mentee discomfort with the recurrence. We propose exploring this in pre-match questionnaires and training. An additional solution is to have a member of the nursing or social work team reach out to both the mentor and mentee if either participant recurs, acknowledging that this is an inflection point in the relationship that can unearth fear and anxiety.

This study was not without limitations. This data is limited to the experiences of women from a single W2W program site in the Midwest. It is unknown how the experiences of peer mentoring may vary based on demography of the participants, geography of the program site, and academic versus community hospital setting. Additionally, we cannot know how in-person mentoring versus virtual mentoring 
may modify the mentoring experience for both mentor and mentee. At the time of interview, each mentor-mentee pair had made contact at least once. It is unknown how the mentorship experience may evolve over time and how the duration of the match relationship influenced the reported mentorship experience of the participants. Further studies are needed to explore these variables and expand the knowledge base of peer mentoring for people with gynecologic cancer.

The W2W peer mentorship program will continue to serve our patients at a time when community support is extremely difficult to access due to COVID-19. Modifying the program training to respond to perspectives shared by our program participants will enhance forthcoming iterations of this highly valued program for future mentor and mentee matches through the pandemic and beyond.

Author contribution HM secured funding. HM, JVB, and LS contributed to concept and design. HM collected data. HM, JVB, and LS performed analysis. HM, JVB, and LS wrote the manuscript, approved the final version, and are accountable for all aspects of the work.

Funding This research was generously supported by the Clendening Summer Fellowship at the University of Kansas School of Medicine and through the Division of Obstetrics and Gynecology at the University of Kansas Health System.

Data availability Not applicable.

Code availability Not applicable.

\section{Declarations}

Ethics approval University of Kansas Medical Center IRB no. 145558.

Consent to participate All participants verbally consented to participating in this research study after an informed consent process.

Consent for publication Not applicable.

Conflict of interest Dr. Spoozak reports non-financial support from Intuitive Surgical outside of the submitted work.

\section{References}

1. Manne S, Rini C, Rubin S, Rosenblum N, Bergman C, Edelson M, Hernandez E, Carlson J, Rocereto T (2008) Long-term trajectories of psychological adaptation among women diagnosed with gynecological cancers. Psychosom Med 70(6):677-687. https:// doi.org/10.1097/PSY.0b013e31817b935d

2. Norton TR, Manne SL, Rubin S, Hernandez E, Carlson J, Bergman C, Rosenblum N (2005) Ovarian cancer patients' psychological distress: the role of physical impairment, perceived unsupportive family and friend behaviors, perceived control, and self-esteem. Am Psychol Assoc. https://doi.org/10.1037/0278-6133.24.2.143
3. Hersch J, Juraskova I, Price M, Mullan B (2009) Psychosocial interventions and quality of life in gynaecological cancer patients: a systematic review. Psychooncology 18(8):795-810. https://doi. org/10.1002/pon.1443

4. Lutgendorf SK, Anderson B, Ullrich P, Johnsen EL, Buller RE, Sood AK, Sorosky JI, Ritchie J (2002) Quality of life and mood in women with gynecologic cancer: a one year prospective study. Cancer 94(1):131-140. https://doi.org/10.1002/cncr.10155

5. Pistrang N, Jay Z, Gessler S, Barker C (2012) Telephone peer support for women with gynaecological cancer: recipients' perspectives. Psychooncology 21(10):1082-1090. https://doi.org/10. 1002/pon.2005

6. Heisler M (2006) Building peer support programs to manage chronic disease: seven models for success. https://www.chcf.org/ wp-content/uploads/2017/12/PDF-BuildingPeerSupportPrograms. pdf. Accessed 3/6/2021 2021

7. Moulton A, Balbierz A, Eisenman S, Neustein E, Walther V, Epstein I (2013) Woman to woman: a peer to peer support program for women with gynecologic cancer. Soc Work Health Care 52(10):913-929. https://doi.org/10.1080/00981389.2013.834031

8. Louisa M, Hoey SCI, White VM, Jefford M (2007) Systematic review of peer-support programs for people with cancer. Patient Educ Couns 70(3):315-337

9. Macvean ML, White VM, Sanson-Fisher R (2008) One-to-one volunteer support programs for people with cancer: a review of the literature. Patient Educ Couns 70(1):10-24. https://doi.org/10. 1016/j.pec.2007.08.005

10. Woman to woman peer support. Ovarian Cancer Research Alliance. https://ocrahope.org/patients/peer-support-woman-towoman/. Accessed 01/30/2021

11. Sandelowski M (2000) Whatever happened to qualitative description? Res Nurs Health 23(4):334-340. https://doi.org/10.1002/ 1098-240x(200008)23:4\%3c334::aid-nur9\%3e3.0.co;2-g

12. Bleakley A (2005) Stories as data, data as stories: making sense of narrative inquiry in clinical education. Med Educ 39(5):534-540. https://doi.org/10.1111/j.1365-2929.2005.02126.x

13. Ltd QIP (2012) NVivo. 12 edn

14. Cancer Hope Network. https://www.cancerhopenetwork.org/. Accessed 1/30/2021

15. Cancer hotline. Richard and Annette Bloch Family Foundation. http://blochcancer.org/about/cancer-hot-line/. Accessed 1/30/2021

16. Moran HK, Brooks JV, Spoozak L (2020) Undergoing active treatment for gynecologic cancer during COVID-19: a qualitative study of the impact on healthcare and social support. Gynecol Oncol Rep 34:100659. https://doi.org/10.1016/j.gore.2020.100659

17. Huntingdon B, Schofield P, Wolfowicz Z, Bergin R, Kabel D, Edmunds J, Penberthy S, Juraskova I (2016) Toward structured peer support interventions in oncology: a qualitative insight into the experiences of gynaecological cancer survivors providing peer support. Support Care Cancer 24(2):849-856. https://doi.org/10. 1007/s00520-015-2853-Z

18. Arians N, Foerster R, Rom J, Uhl M, Roeder F, Debus J, Lindel K (2016) Outcome of patients with local recurrent gynecologic malignancies after resection combined with intraoperative electron radiation therapy (IOERT). Radiat Oncol 11:44-44. https:// doi.org/10.1186/s13014-016-0622-x

Publisher's note Springer Nature remains neutral with regard to jurisdictional claims in published maps and institutional affiliations. 